\title{
EELGRASS MAPPING IN ATLANTIC CANADA USING WORLDVIEW-2 IMAGERY
}

\author{
D. Forsey ${ }^{1}$, B. Leblon ${ }^{1, *}$, A. LaRocque ${ }^{1}$, M. Skinner ${ }^{2}$, A. Douglas ${ }^{3}$ \\ ${ }^{1}$ Faculty of Forestry and Environmental Management, University of New Brunswick, Fredericton (NB), E3B 5A3, Canada \\ - (dforsey, leblon, larocque)@unb.ca \\ ${ }^{2}$ Stantec Consulting Ltd., 40 Highfield Park Drive 102-40, Dartmouth (NS), B3A 0A3, Canada - Marc.Skinner@ stantec.com \\ ${ }^{3}$ Southern Gulf of St. Lawrence Coalition on Sustainability, Stratford (PEI), C1B 1L1, Canada - Coalition.sgsl@gmail.com
}

Commission III, WG III/7

KEY WORDS: Eelgrass mapping, Atlantic Canada, WorldView-2, Maximum Likelihood, Random Forests

\section{ABSTRACT:}

Eelgrass (Zostera marina L.) is a marine angiosperm plant that grows throughout coastal areas in Atlantic Canada. Eelgrass meadows provide numerous ecosystem services, and while they have been acknowledged as important habitats, their location, extent, and health in Atlantic Canada are poorly understood. This study examined the effectiveness of WorldView-2 optical satellite imagery to map eelgrass presence in Tabusintac Bay, New Brunswick (Canada), an estuarine lagoon with extensive eelgrass coverage. The imagery was classified using two supervised classifiers: the parametric Maximum Likelihood Classifier (MLC) and the non-parametric Random Forests (RF) classifier. While Random Forests was expected to produce higher classification accuracies, it was shown not to be much better than MLC. The overall validation accuracy was $97.6 \%$ with RF and $99.8 \%$ with MLC.

\section{INTRODUCTION}

Seagrasses are angiosperm plants that grow in brackish and saltwater systems found in coastal areas across the globe. There are approximately 60 species of seagrass worldwide. Atlantic Canada is within the Temperate North Atlantic bioregion, which has only five species: Ruppia maritima L., Zostera marina L., Zostera noltii Horneman, Cymodocea nodosa Asch, Halodule wright Asch, with $Z$ marina, being the most common (Short et al., 2007a, 2007b). Eelgrass beds are the ecological base of many nearshore marine ecosystems (Heck, Orth, 2006) and are highly sensitive to environmental fluctuations, making them possible indicators of nearshore ecosystem health and the effects of climate change and other anthropogenic influences on marine and estuarine ecosystems (Thom et al., 2013). In facing numerous human-driven influences, eelgrass ecosystems have been declining globally for at least the last 100 years (Waycott et al., 2009). Throughout Atlantic Canada, declines of $30 \%$ to $95 \%$ have been reported for several bays in the recent decade (DFO, 2009).

To properly monitor eelgrasses and to study the impacts of anthropogenic disturbances on their distribution, it is important to have a reliable method of accurately mapping the extent of eelgrass beds (Hogrefe et al., 2014). Acoustic methods have been used to create high-quality sonographs on a scale relevant to eelgrass mapping (Kenny et al., 2003), but acoustics data are acquired with very expensive equipment that cannot be used under adverse weather conditions or require specialist knowledge to be processed. Also, acoustic surveys are made of transects that may provide insufficient coverage on temporal and spatial scales and require interpolation methods. The same applies to the bathymetric lidar data (Webster et al., 2015, Collins et al., 2016). Optical imagery can cover the entirety of a study area and has been extensively used to map benthic habitats (Orth, Moore, 1984). While aerial photographs have been used with success for more than 20 years (Mumby et al., 1997), the use of optical satellite images has been ongoing only since the launch of the
Landsat MSS satellite in 1972 (Lyons et al., 2012). Satellite imagery provides a larger level of coverage at a smaller cost when compared to aerial photographs (Dekker et al., 2006, Hossain et al., 2015) and does not require interpolation like other methods. Most published studies that use optical satellite imagery have occurred only recently in Canada (O'Neill, Costa, 2013, Reshitnyk et al., 2014; Stantec, 2014; 2016; Barrell et al., 2015). Temperate water poses additional challenges for mapping eelgrass compared to tropical and sub-tropical waters because they tend to have lower clarity, which allows for lower resolution between features and low light penetration, which allows for mapping at shallower depths. (O'Neill, Costa, 2013, Reshitnyk et al., 2014). In most of the aforementionned studies, the classifier that was employed is the standard supervised Maximum likelihood classifier (MLC). Such a classifier has the inconvenience of requiring a normal data distributionbut not with Random Forests (RF), which is a non-parametric supervised classifier (Breiman, 2001). RF was showed to outperform MLC in several land cover studies (Pal, 2005, Gislason et al., 2006, Waske, Braun, 2009, LaRocque et al., 2014).

The goal of this study is to compare RF and MLC to map eelgrass bed distribution in Tabusintac Bay, New Brunswick (Canada), using one WorldView-2 (WV-2) image acquired at low tide. One of the challenges of mapping eelgrass beds in Tabusintac Bay is that it is an estuarine lagoon having a temperate climate where light penetration is generally low. To assess the potential change in the eelgrass distribution in Tabusintac Bay over time, the resulting map will be compared to a previous map produced by the interpretation of air photographs (Mahoney, Hanson, 2008).

\section{MATERIAL AND METHODS}

\subsection{Study area}

Tabusintac Bay (Figure 1) is a $25 \mathrm{~km}^{2}$ shallow estuary and lagoon system located on the northeastern coast of New Brunswick (N $\left.47^{\circ} 20^{\prime} 21^{\prime \prime}, \mathrm{W} 64^{\circ} 55^{\prime} 42^{\prime \prime}\right)$. The adjacent region hosts a diverse

\footnotetext{
* Corresponding author
} 
assemblage of habitats, including estuarine flats, peat bogs, saline ponds, and wetlands, while the lagoon area itself is dominated by extensive eelgrass (Zostera marina) beds that support many species of commercial and recreational importance. The wave energy within the estuary is generally low, thanks to an extensive and dynamic bar of sand dunes and islands which shelters the area from wave action from the Gulf of St. Lawrence. The bottom consists of fine-grained sediments like mud and sand, making it an ideal substrate for eelgrass growth. The estuary is generally shallow at 0 to $2 \mathrm{~m}$ deep, though a 2 to $5 \mathrm{~m}$ deep channel cuts through the lower portion of the region, which allows boat access to the Northumberland Strait (Webster et al., 2015, Stantec, 2014, Stantec, 2016). The site has been identified under the Ramsar Convention on wetlands as an international area of importance due to high levels of waterfowl visitation and uses during spring and fall migration periods, with some of these species depending directly on eelgrass for food (Ramsar, 2001). The dune system is also the home to one of the largest common tern colonies in Atlantic Canada and has been the site of piping plover (Charadrius melodus) nests (IBA Canada, 2013).

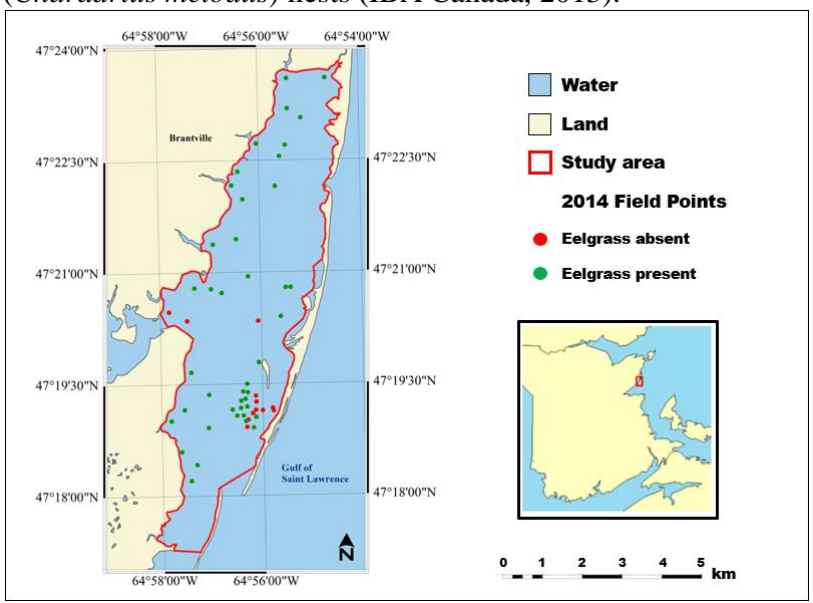

Figure 1. Location of the Tabusintac Bay and the eelgrass presence/absence GPS points of 2014 collected by (Stantec (2014) and used in this study.

\subsection{Data}

We utilized one WorldView-2 (WV-2) optical image acquired at $15 \mathrm{~h} 50$ AST (18h50 GMT) on September $24^{\text {th }}, 2014$. The image was taken at low tide $(0.38 \mathrm{~m})$ and covered an area of approximately $13 \mathrm{~km}$ long and $3 \mathrm{~km}$ wide, centred on Lat. $\mathrm{N} 47^{\circ}$ 22 ' 36", and Long. W $64^{\circ} 56^{\prime} 08^{\prime \prime}$. The air temperature was $14.5^{\circ} \mathrm{C}$, with a wind speed of $13 \mathrm{~km} / \mathrm{h}$ and at a direction of $210^{\circ}$. The solar azimuth was $179^{\circ}$. The image has nine optical bands: panchromatic $(450-800 \mathrm{~nm})$, coastal blue $(400-450 \mathrm{~nm})$, blue $(450-510 \mathrm{~nm})$, green $(510-580 \mathrm{~nm})$, yellow $(585-625 \mathrm{~nm})$, red $(630-690 \mathrm{~nm})$, red-edge $(705-745 \mathrm{~nm})$, near-infrared $1(770-895$ $\mathrm{nm})$, and near-infrared $2(860-1040 \mathrm{~nm})$. The satellite sensor has a resolution at the nadir of $0.46 \mathrm{~m}$ for the panchromatic band and $1.85 \mathrm{~m}$ for multispectral bands. It has a swath width of $16 \mathrm{~km}$ from the nadir and a dynamic radiometric range of 11 bits per pixel.

Field data were collected during a two-day field survey (Stantec, 2014) between September $24^{\text {th }}$ and $26^{\text {th }}, 2014$, coinciding with the acquisition of the image (Figure 1). The study area was divided into an equally sized grid of $1 \mathrm{~km}$ wide-tessellated hexagons, and a single area of interest was randomly selected within each hexagon. This division allowed for the whole study area to be sampled while maintaining randomness (Figure 1). A total of 55 sites were surveyed. At each site, GPS coordinates were recorded using a WAAS-enabled chart plotting unit (Garmin GPSmap® 531s, Garmin International Inc., Olathe, Kansas, USA), and pictures were taken using a downward-facing underwater Deep Blue Pro $\odot$ drop video camera (Deep Blue Pro Splash Cam, Ocean Systems Inc., Everett, WA, USA) attached to a $0.25 \mathrm{~m}^{2}$ quadrat frame. Additional samples were collected by Stantec (2014) in a specific area of interest, located in the southwestern portion of the study area.

\subsection{Pre-Classification Image Processing}

All the image processing was performed in PCI Geomatica ${ }^{\circledR}$ software (PCI Geomatics, 2018), except the atmospheric correction, which was done in ENVI® 5.1 software (Exelis Visual Information Solutions, 2013). The digital numbers (DNs) of the input image were converted into Top of the Atmosphere (TOA) reflectance. First, DNs were converted to radiance by applying Equation 1 that uses band-specific calibration gain and offset parameters, which were extracted from the image metadata (Digital Globe, 2010):

$$
L_{\lambda}=M_{L} * D N+A_{L}
$$

where $\quad \mathrm{L}_{\lambda}=$ TOA spectral radiance $\left(\mathrm{W} \cdot \mathrm{m}^{-2} \cdot \operatorname{srad}^{-1} \cdot \mu \mathrm{m}^{-1}\right)$

$\mathrm{M}_{\mathrm{L}}=$ Gain $\left(\mathrm{W} \cdot \mathrm{m}^{-2} \cdot \mathrm{srad}^{-1} \cdot \mu \mathrm{m}^{-1}\right)$

$\mathrm{A}_{\mathrm{L}}=\operatorname{Offset}\left(\mathrm{W} \cdot \mathrm{m}^{-2} \cdot \operatorname{srad}^{-1} \cdot \mu \mathrm{m}^{-1}\right)$

$\mathrm{DN}=$ digital number (dimensionless)

The TOA radiance was then converted into TOA reflectance, which represents the radiation that has travelled from the sun through the atmosphere, reflected off the surface of the earth and interacts with the sensor. This conversion uses Equation 2 and compensates for the relative position of the sun and the earth, at the zenith:

$$
\rho_{\lambda}=\frac{L_{\lambda} * \pi *\left(d_{E S}\right)^{2}}{\mathrm{E} * \cos (\theta \mathrm{z})}
$$

where $\quad \rho_{\lambda}=$ TOA reflectance (dimensionless)

$$
\begin{aligned}
& \rho_{\lambda}=\text { TOA reflectance }(\text { dimensionless }) \\
& \mathrm{E}_{\lambda}=\text { Solar spectral irradiance }\left(\mathrm{W} \cdot \mu \mathrm{m}^{-1}\right) \\
& \mathrm{L}_{\lambda}=\text { TOA spectral radiance }\left(\mathrm{W} \cdot \mathrm{m}^{-2} \cdot \mathrm{srad}^{-1} \cdot \mu \mathrm{m}^{-1}\right) \\
& \mathrm{d}_{\mathrm{ES}}=\text { distance earth-sun }(\mathrm{m}) \\
& \theta_{\mathrm{z}}=\text { solar zenith angle }(\mathrm{rad})
\end{aligned}
$$

TOA reflectance has an atmospheric component that is caused by the effect of light reflection and scattering from atmospheric particles and by the atmosphere itself and needs to be removed. The atmospheric corrections of the TOA reflectance image were performed with the Fast Line-of-Sight Atmospheric Analysis of Spectral Hypercubes (FLAASH) module based on the Berk et al. (1998)'s algorithm and embedded in ENVI ${ }^{\circledR} 5.1$ software (Exelis Visual Information Solutions, 2013). We selected the temperate atmosphere and maritime aerosol models.

The image was georeferenced and converted to the New Brunswick Double Stenographic Projection referenced to the North American Datum of 1983 (NAD83) related to the Canadian Spatial Reference System (CSRS). The image was pansharpened using the PANSHARP algorithm of PCI Geomatica ${ }^{\circledR}$ (PCI Geomatics, 2018) developed by Zhang (2002) to downscale the multispectral bands to $0.5 \mathrm{~m}$ spatial resolution by combining the panchromatic band and the multispectral bands. High spatial resolution is key for capturing the spatial variability and patchiness of eelgrass meadows due to the potentially complex distribution of eelgrass beds in the lagoon. A land mask was created to limit the image classification to underwater features 
using the Normalized Difference Water Index (NDWI), which was calculated, as in McFeeters (1996).

Given that the aim of this study is to map eelgrass beds which are chlorophyllous elements in the scene, it is advantageous to consider vegetation indices in order to exploit the higher reflectance in the green and near-infrared bands of chlorophyllous elements compared to non-chlorophyllous elements. While near-infrared radiation is expected to be readily absorbed by water, there are portions of the study area that include exposed eelgrass at low tide which can reflect this radiation. The vegetation indices considered in this study are listed in Table 1.

\begin{tabular}{|c|c|c|c|}
\hline Variable & Name & Formula $^{(1)}$ & Reference \\
\hline DVI & $\begin{array}{l}\text { Difference } \\
\text { Vegetation Index }\end{array}$ & NIR-R & Tucker (1979) \\
\hline GDVI & $\begin{array}{l}\text { Green Difference } \\
\text { Vegetation Index }\end{array}$ & NIR-G & Sripada et al. (2006) \\
\hline GNDVI & $\begin{array}{l}\text { Green Normalized } \\
\text { Difference } \\
\text { Vegetation Index }\end{array}$ & $\begin{array}{c}\text { (NIR- } \\
\mathrm{G}) /(\mathrm{NIR}+\mathrm{G})\end{array}$ & $\begin{array}{l}\text { Buschmann, Nagel } \\
\text { (1993) }\end{array}$ \\
\hline NDVI & $\begin{array}{l}\text { Normalized } \\
\text { Difference } \\
\text { Vegetation Index }\end{array}$ & $\begin{array}{c}\text { (NIR- } \\
\mathrm{R}) /(\mathrm{NIR}+\mathrm{R})\end{array}$ & Rouse et al. (1974) \\
\hline NG & Normalized Green & G/(NIR+R+G) & Sripada et al. (2006) \\
\hline NR & Normalized Red & R/(NIR+R+G) & Sripada et al. (2006) \\
\hline NNIR & $\begin{array}{l}\text { Normalized Near- } \\
\text { Infrared }\end{array}$ & $\mathrm{NIR} /(\mathrm{NIR}+\mathrm{R}+\mathrm{G})$ & Sripada et al. (2006) \\
\hline RVI & $\begin{array}{l}\text { Ratio Vegetation } \\
\text { Index }\end{array}$ & $\mathrm{NIR} / \mathrm{R}$ & $\begin{array}{l}\text { Birth, McVey } \\
\text { (1968) }\end{array}$ \\
\hline GRVI & $\begin{array}{l}\text { Green Ratio } \\
\text { Vegetation Index }\end{array}$ & NIR/G & Sripada et al. (2006) \\
\hline
\end{tabular}

Table 1. Vegetation indices used in this study

Since the two classifiers tested in the study (RF and MLC) are supervised classifiers, they require delineation of training areas. Small representative training areas for each class (Eelgrass, Deep water, and Sand floor) were delineated over the image based on the large training areas that were previously defined by Stantec (2014) using an object-based segmentation method (Table 2).

\begin{tabular}{|l|c|c|c|c|}
\hline \multicolumn{1}{|c|}{ Class } & $\begin{array}{c}\text { Training } \\
\text { Areas }\end{array}$ & $\begin{array}{c}\text { Area } \\
{\left[\mathrm{m}^{2}\right]}\end{array}$ & Pixels & $\begin{array}{c}\text { GPS } \\
\text { validation sites }\end{array}$ \\
\hline Eelgrass & 430 & 61924 & 15481 & $43^{(1)}$ \\
Deep water & 459 & 61590 & 15398 & \\
Sand floor & 321 & 22052 & 5513 & $12^{(1)(2)}$ \\
\hline Total & 1210 & 145567 & 36392 & 55 \\
\hline
\end{tabular}

(1) According to Stantec (2014);

(2) Has been used for the "eelgrass absent" class

Table 2. Number of training areas with the corresponding area, the pixel count and the number of GPS validation sites for each class, used in this study

When training areas were delineated, care was made to reduce spectral variance in each class while at the same, having enough pixels to represent each class effectively. Training areas were used to compute the class spectral signatures. These spectral signatures were then used to assess the separability between classes through the Jeffries-Matusita (J-M) distance of each class pair (Richards, Jia, 2006).

\subsection{Classification}

The first classifier that was tested is the commonly used Maximum Likelihood Classifier (MLC). This classifier was performed using the MLC algorithm of PCI Geomatica 2018®. MLC is a parametric classifier assuming a Gaussian distribution of grey level values for each class and the same probability of occurrence for each class in the image. It classifies each pixel $\mathrm{x}$ in class $\mathrm{i}$ by maximizing the following discriminant function (Strahler, 1980) (Equation 3):

$$
g_{i}(x)=\ln (p(i))-\frac{1}{2}\left(X-M_{i}\right)^{t} \sum_{i}^{-1}\left(X-M_{i}\right)-\frac{1}{2} \ln \left[\left|\sum i\right|\right]-\frac{k}{2} \ln (2 \pi)
$$

where $\quad g_{i}(x)=$ discriminant function for class $\mathrm{i}$ and pixel $\mathrm{x}$ $\mathrm{p}(\mathrm{i})=$ a priori probability for class I

$\mathrm{X}=$ grey level value of pixel $\mathrm{x}$ in each input image

$\mathrm{M}_{\mathrm{i}}=$ mean vector for class $\mathrm{i}$

$\sum_{\mathrm{i}}=$ covariance matrix for any class

$\left|\Sigma_{1}\right|=$ determinant of the covariance matrix $\Sigma_{1}$

$\Sigma_{1}^{-1}=$ inverse of the covariance matrix $\Sigma_{\mathrm{I}}$

$\left(\mathrm{X}-\mathrm{M}_{\mathrm{i}}\right)^{\mathrm{t}}=$ transposed matrix of $\left(\mathrm{X}-\mathrm{M}_{\mathrm{i}}\right)$

$\mathrm{k}=$ number of input images used in the classification

The second classifier is Random Forests (RF) is a non-parametric classification algorithm (Breiman, 2001). Originally designed for use by the machine learning community, this algorithm is becoming increasingly popular for remote sensing applications showing numerous advantages when compared to other classical classification methods, such as MLC (Pal, 2005, Gislason et al., 2006, Waske, Braun, 2009, LaRocque et al., 2014). RF classifier generates a series of decision trees, which are predictive models that use a set of binary rules to calculate a target value. The complexity of the decision tree is directly related to the number of sources of data, in our case, the number of image layers being used. Each tree uses a randomized subset of the input data, and each of the categories produced by each tree is slightly different. In the RF algorithm, hundreds of trees are produced, and the pixels are classed based on the agreement between trees. Also, $\mathrm{RF}$ is not sensitive to noise or over-classifying and gives an estimate of the importance of each input image for the classification (Gislason et al., 2006, Waske, Braun, 2009). The specific algorithm used for this study was developed in the $\mathrm{R}$ programming language (R Development Core Team, 2016). It is based on the "Random Forest" code written by Horning (2010) and adapted by the third author. The RF code we used has two versions: all-polygon and sub-polygon. The all-polygon version uses $100 \%$ of the training areas to define class training areas, while the sub-polygon version randomly selects a user-defined number of training area pixels from each class. Following Byatt et al. (2018), we used the all-polygon version because it gives a higher mapping accuracy using all the training areas in the classification method. Another advantage of using RF is that the algorithm outputs a variable importance plot. This plot displays the weighted mean decrease in error that indicates how much an individual variable input is used by the RF classifier to make its prediction.

\subsection{Classification and Validation Accuracy Assessment}

Classification accuracy was assessed first by comparing Areas of Interest (AOI)s with the equivalent class in the imagery. This comparison was performed under the form of a "confusion matrix" or "error matrix", where each cell expresses the number of pixels classified inside the class defined by the training areas (Congalton, 1991). The confusion matrix allows computing individual class User's and Producer's accuracies and their related errors (omission and commission). The User's class accuracy corresponds to the probability that a pixel of the classified image is in the correct class, the associated number of misclassified pixels being pixels classified in the incorrect class (error of omission). The Producer's accuracy measures the probability that a reference pixel is effectively well classified, the associated number of misclassified pixels being pixels that belong to another class (error of commission). The overall 
accuracy is the average of individual class User's or Producer's accuracies, weighted by the size of the class in the classified or reference image. The kappa coefficient is defined as a weighted measure of agreement between the numbers of well-classified pixels, where a value close to $0 \%$ corresponds to a classification that is no better than what could be expected by chance and a value closer to $100 \%$ indicates a good classification accuracy (Cohen, 1960).

\section{RESULTS}

\subsection{Spectral Separability}

Table 3 gives the class separability or J-M distances between the three classes that were computed with the spectral signatures related to the eight original WV-2 bands. The mean J-M distance is 1.983. All the classes had a J-M distance greater than 1.95, indicating a good spectral separation between classes. The lowest J-M distance occurred between the Deep water and Sand floor classes (1.952), while the highest occurred between the Eelgrass and Sand floor classes (1.999).

\begin{tabular}{|c|c|c|}
\hline Class & Deep water & Eelgrass \\
\hline Eelgrass & 1.997 & \\
Sand floor & 1.952 & 1.999 \\
\hline
\end{tabular}

Table 3. J-M distances computed for the eight original bands of the WV-2 image.

Figure 2 shows the mean TOA reflectance for each class as a function of the WV-2 band, as extracted from the images using the corresponding training areas. All the classes followed a general trend that matches how we would expect the light to be absorbed in water, with higher absorption (weaker reflectance) in the longer wavelengths, and gradually less absorption (stronger reflectance) in the shorter wavelengths. The Deep water class had the lowest reflectance in the red-edge, NIR-1, and NIR-2 bands, compared to the other two classes. This is likely because the Sand Floor and Eelgrass classes were delineated over shallower areas where light penetration was higher. The Sand Floor class followed a similar decreasing reflectance pattern from the coastal to the NIR bands, though the reflectance was generally higher. From the coastal to yellow wavelengths, the Eelgrass class distinctly had the lowest reflectance among all the classes, including the Deep water class.

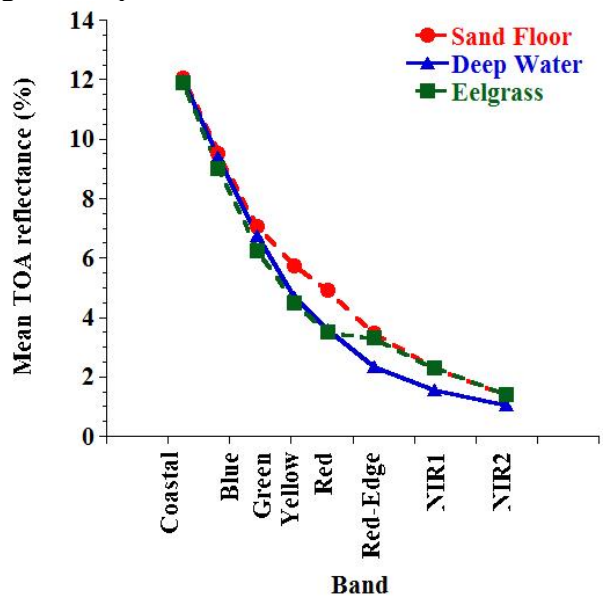

Figure 2. Mean TOA reflectance for each class as a function of the WV-2 band.

Among all the vegetation indices considered in the study, only DVI, RVI and GDVI all showed good separability between classes (Figure 3). DVI and RVI were both calculated using the
NIR-1 and Red bands, while GDVI used both the NIR and Green bands in its calculation. The NIR-1 band had a good spectral separability between the Deep water class and the other classes, while the case of the red band, the Sand Floor class was most separated from the others. (Figure 3). In the case of the green band, there was relatively little separability between the classes.

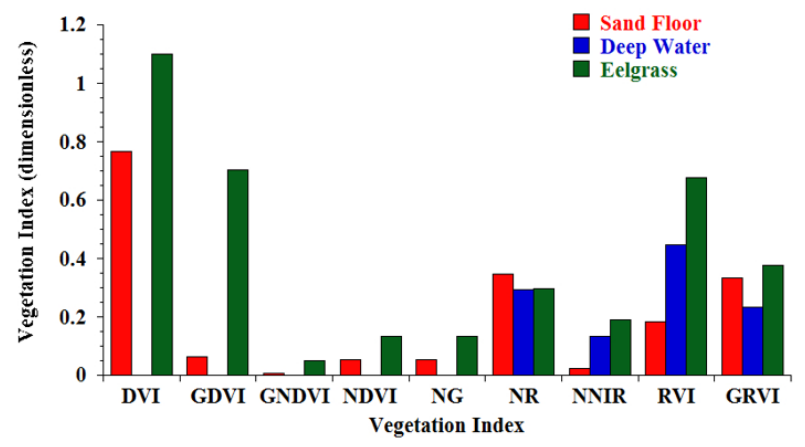

Figure 3. Mean value of the vegetation indices computed with the WV-2 band images as a function of the class.

\subsection{Classification}

When only the original eight bands were used, the overall classification accuracy was $98.55 \%$ with the MLC classifier and $99.86 \%$ with the RF classifier. The corresponding kappa coefficients were $97.65 \%$ and $99.80 \%$, respectively. The individual class Producer's and User's accuracies for both classifiers were also very high and are never below 95\%, as shown in the confusion matrices (Tables 4 and 5). The Sand floor class has the lowest User's and Producer's accuracies, and the Deep water class had the highest accuracies, the Eelgrass class having intermediate accuracies, though the differences were minor (Tables 4 and 5). The comparison between the detailed confusion matrices of both tables shows that there was a higher number of well-classified pixels and a lower number of misclassified pixels for the RF classifier (Table 5) than for the MLC classifier (Table 4). However, we only show here the MLCclassified image produced because of the minimal difference between both images (Figure 4).

\begin{tabular}{|l|c|c|c|c|}
\hline \multicolumn{1}{|c|}{ Class } & Eelgrass & $\begin{array}{c}\text { Deep } \\
\text { water }\end{array}$ & $\begin{array}{c}\text { Sand } \\
\text { floor }\end{array}$ & $\begin{array}{c}\text { User's } \\
\text { accuracy [\%] }\end{array}$ \\
\hline Eelgrass & 241798 & 1858 & 4037 & 97.80 \\
Deep water & 3153 & 243181 & 25 & 99.70 \\
Sand floor & 353 & 0 & 87856 & 97.50 \\
\hline $\begin{array}{l}\text { Producer's } \\
\text { accuracy [\%] }\end{array}$ & 98.81 & 99.50 & 95.26 & \\
\hline
\end{tabular}

Table 4. Confusion matrix (in terms of number of pixels) and associated accuracies when the MLC classifier is applied to the 8-band images

\begin{tabular}{|l|c|c|c|c|}
\hline \multicolumn{1}{|c|}{ Class } & Eelgrass & $\begin{array}{c}\text { Deep } \\
\text { water }\end{array}$ & $\begin{array}{c}\text { Sand } \\
\text { floor }\end{array}$ & $\begin{array}{c}\text { User's } \\
\text { accuracy [\%] }\end{array}$ \\
\hline Eelgrass & 247232 & 310 & 151 & 99.81 \\
Deep water & 127 & 246226 & 6 & 99.95 \\
Sand floor & 194 & 2 & 86522 & 99.77 \\
\hline Producer's & 99.87 & 99.87 & 99.82 & \\
accuracy [\%] & & & \\
\hline
\end{tabular}

Table 5. Confusion matrix (in terms of number of pixels) and associated accuracies when the RF classifier is applied to the 8-band images

The RF algorithm has the advantage of giving a variable importance plot that ranks the input features as a function of their 
importance in the classification (Figure 5). The most important bands for the classification were the green $(510-580 \mathrm{~nm})$, red $(630-690 \mathrm{~nm})$ and coastal $(400-450 \mathrm{~nm})$ bands, while the least important bands were the near-infrared 1 (770 - $895 \mathrm{~nm})$, blue $(450-510 \mathrm{~nm})$, and yellow (585 - $625 \mathrm{~nm}$ ) bands (Figure 5a). The green band allowed some spectral separability between the Deep Water and Eelgrass classes (Figure 3) and was the band that most distinguishes the two. The green and coastal bands have the lowest rates of attenuation in shallow water, especially when compared to the longer wavelength bands.

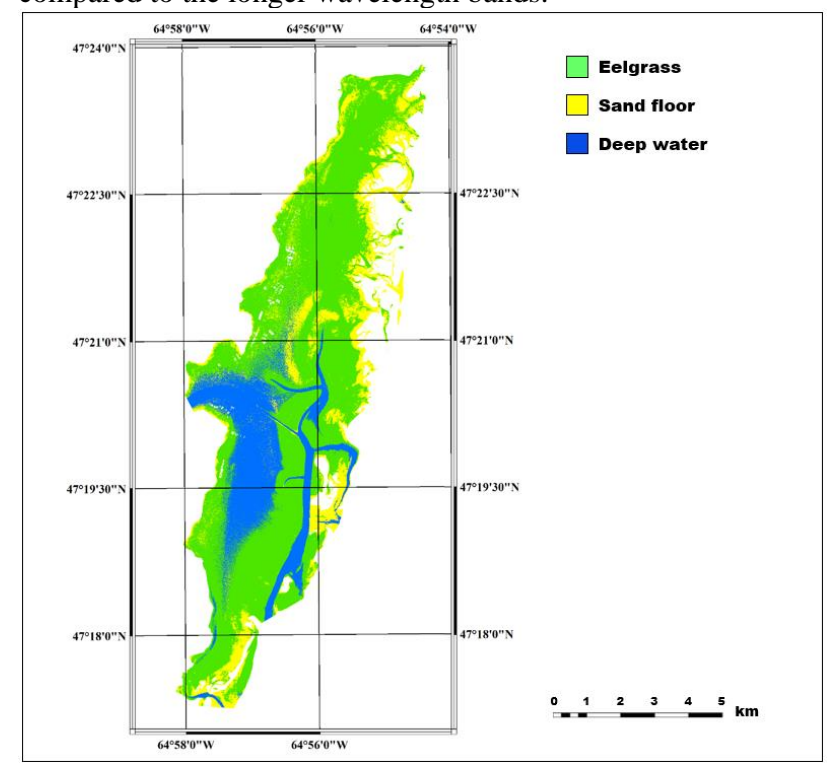

Figure 4. Eelgrass bed map produced by applying the MLC classifier to the eight bands of the WorldView-2 image.

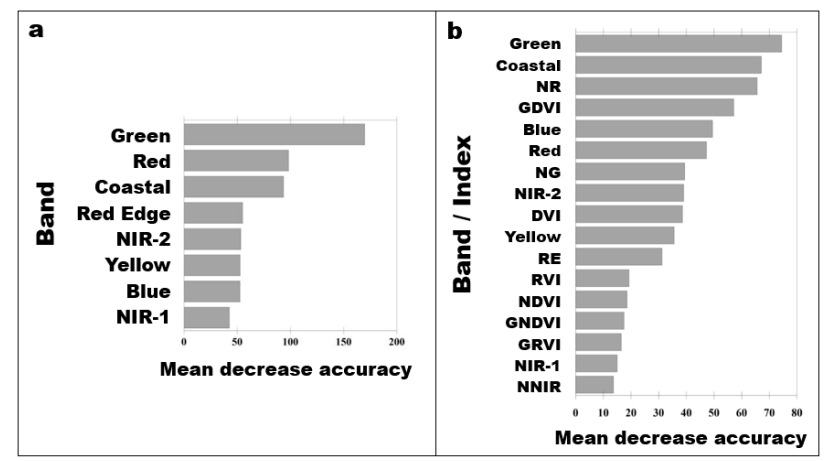

Figure 5. Variable importance plot computed by RF applied: a) to the eight original bands of the WV-2 image; $b$ ) the combination of the original 8-bands and the related vegetation indices.

With the addition of vegetation indices to the image combination (Table 6), the overall classification accuracy and the kappa coefficient with MLC were very low (42.65\% and $0 \%$, respectively). According to the confusion matrix of Table 6 , the misclassification in the case of the MLC because all the pixels were classified in the Eelgrass class. This misclassification demonstrated how MLC could not be effectively used with a variety of different data types. By contrast, the RF classifier produced higher classification overall accuracy $(99.83 \%)$ and the kappa coefficient $(99.70 \%)$ than MLC, but they were not higher than when RF used only the eight original bands (Table 5).
The variable importance plot (Figure 5b) showed that, among all the vegetation indices, the most important ones were the Normalized Red (NR) and the Green Difference Vegetation (GDVI). This was likely because both used the green band in their computation, although another green-based vegetation index (NR) did not exhibit a large separability between classes. The other vegetation indices did not seem to be very important in the RF image classification (Figure 5b).

\begin{tabular}{|l|c|c|c|c|}
\hline \multicolumn{1}{|c|}{ Class } & Eelgrass & $\begin{array}{c}\text { Deep } \\
\text { water }\end{array}$ & $\begin{array}{c}\text { Sand } \\
\text { floor }\end{array}$ & $\begin{array}{c}\text { User's } \\
\text { accuracy [\%] }\end{array}$ \\
\hline Eelgrass & 247693 & 0 & 0 & 100 \\
Deep water & 246359 & 0 & 0 & 0 \\
Sand floor & 86714 & 0 & 0 & 0 \\
\hline Producer's & 42,65 & 0 & 0 & \\
accuracy [\%] & & 0 & \\
\hline
\end{tabular}

Table 6. Confusion matrix (in terms of number of pixels) and associated accuracies when the MLC is applied to the 8-band images and the related vegetation indices

\subsection{Field Validation}

This validation and the subsequent analysis are done on the MLC-classified image based on the eight bands given the excellent classification accuracies (Table 7). The validation was done by comparing it to the GPS validation sites. We achieved excellent values for the overall accuracy $(96.36 \%)$ and the kappa coefficient $(91.00 \%)$. The related confusion matrix shows that only a few sites were poorly classified (Table 7).

\begin{tabular}{|l|c|c|c|}
\hline \multicolumn{1}{|c|}{ Class } & $\begin{array}{c}\text { Eelgrass } \\
\text { present }\end{array}$ & $\begin{array}{c}\text { Eelgrass } \\
\text { absent }\end{array}$ & $\begin{array}{c}\text { User's } \\
\text { accuracy [\%] }\end{array}$ \\
\hline $\begin{array}{l}\text { Eelgrass present } \\
\text { Eelgrass absent }\end{array}$ & $\begin{array}{c}40 \\
0\end{array}$ & 2 & $\begin{array}{c}\% \\
13\end{array}$ \\
\hline $\begin{array}{l}\text { Producer's } \\
\text { accuracy [\%] }\end{array}$ & 100.00 & 86.67 & 100.00 \\
\hline
\end{tabular}

Table 7. Confusion matrix between GPS field sites collected in 2014 by Stantec Consulting Ltd and the MLC classified image using the 8-band images

\subsection{Comparison with the eelgrass bed extent of 2008}

The eelgrass bed distribution map obtained by classifying the 8 original bands of the WV-2 image was compared to the one of Mahoney and Hanson (2008) established from aerial photographs.

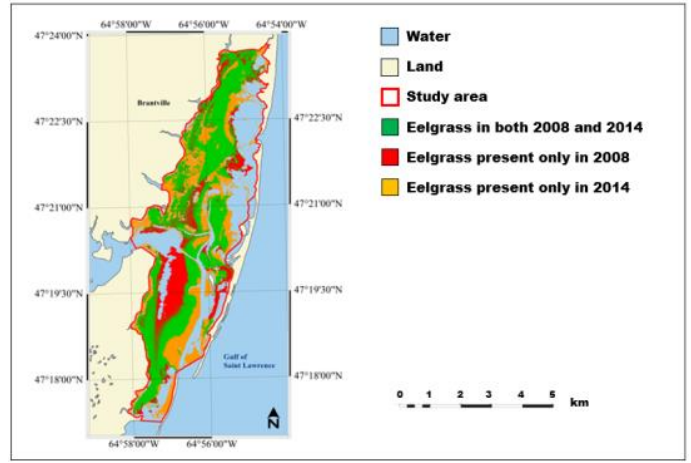

Figure 6. Comparison of the eelgrass extent between 2008 and 2014.

The total eelgrass bed extent increased slightly of about $2 \mathrm{~km}^{2}$ between 2008 and 2014. As shown in Figure 6, $9.68 \mathrm{~km}^{2}$ of eelgrass were present in both 2008 and 2014. There were 3.57 $\mathrm{km}^{2}$ of eelgrass present only in 2008 and $5.66 \mathrm{~km}^{2}$ of eelgrass 
present only in 2014. Figure 6 also shows a difference for the sandbar area that could be due to changes in the shape and extent of the sandbar over time, as described by CBCL Ltd (2014).

\section{DISCUSSIONS}

Our results showed that WV-2 images acquired at low tide are suitable for mapping eelgrass beds in shallow bays such as in Tabusintac. Indeed, the WV-2 sensor has a number, width, and overlap of spectral bands that are suitable for eelgrass bed and benthic mapping. The RF outputs shows that the green (506-586 $\mathrm{nm})$ and coastal bands (396-458 nm) were amongst the most important input data in the classification (Figure 5). With the MLC classifier applied only to the 8-band WV-2 image, our overall classification accuracy $(98.55 \%)$ was higher than those obtained by Stantec (2016) (70\%) who used the same image, but different training areas and the MLC algorithm of ArcGIS ${ }^{\circledR}$ (ESRI, 2014). Our overall classification accuracies are on the same order of magnitude as those of Pu et al. (2012), Chen et al. (2016), Hossain et al. (2019), and Wilson et al. (2019).

While RF was expected to produce higher classification accuracies, it was shown not to be better than MLC when only the eight bands of the WV-2 image were used. This result is contradictory to other studies comparing MLC and RF (i.e., LaRocque et al., 2014; Byatt et al., 2018). One of the major discrepancies with these previous studies is the diversity in the input data. In our analysis, we only utilized optical data that have a normal distribution, while LaRocque et al. (2014) and Byatt et al. (2018) used a more complex dataset made of optical imagery, radar imagery, and topographic data, with some data having a non-normal distribution such as the radar data.

We expected that the inclusion of vegetation indices would improve the overall classification accuracy, as it is often the case in land studies, but there did not seem to be an advantage of using these indices, especially with the MLC classifier. With RF, among all the vegetation indices considered in the studies, the most important ones were two vegetation indices that use the green band in their computation, i.e., the Normalized Red (NR) and the Green Difference Vegetation (GDVI), although NR does not exhibit a large separability between classes by contrast to GDVI. The lack of improvement with the vegetation indices is likely because our study deals with water-related ecosystems, and these indices were developed for land studies to highlight the presence of green vegetation or to assess vegetation water content.

The 2014 WV-2-derived map was compared to a map produced from the interpretation of aerial photographs carried out by Mahoney and Hanson (2008). The comparison showed that in some parts of the bay, there was an increase of approximately 6 $\mathrm{km}^{2}$ of eelgrass, but a decrease of approximately $4 \mathrm{~km}^{2}$ in other parts of the bay, resulting in a net increase of $2 \mathrm{~km}^{2}$ for the whole bay. This result agrees with Leblanc et al. (2019), who showed a positive trend in the total eelgrass area in Tabusintac by analysing a temporal series of Landsat images between 1984 and 2017. Tabusintac Bay seems to experience a different evolution in eelgrass beds compared to several bays in the Atlantic Canada, where inter-annual declines ranging from $30 \%$ to $95 \%$ have been reported for the last decade (DFO, 2009).

\section{CONCLUSIONS}

This study tested the use of two supervised classifiers applied to a WV-2 image for mapping eelgrass beds in Tabusintac to assess their respective effectiveness. The classification accuracy of eelgrass maps using WV-2 imagery was not improved by using the RF classifier when compared to MLC. Also, the addition of vegetation indices in the classification did not improve the classification accuracies. The classified image was then compared with the eelgrass distribution map that was established from air photo interpretation (Mahoney, Hanson, 2008). Such comparison shows a net increase of the eelgrass bed area in Tabusintac Bay, which agrees with the results of Leblanc et al. (2019), who mapped changes in eelgrass bed areas between 1984 and 2017 in Tabusintac Bay using a time series of Landsat images.

This study only tested two classifiers (MLC and RF) applied to imagery acquired by a commercial satellite WV-2, and there is the need for future research to examine and assess freely available satellite images such as Sentinel-2. Also, we did not correct the images for sun glint effects described in Zimmerman and Dekker (2006) and the water column effects. There is the need to test if algorithms such as the one of Hedley et al. (2005) can be used for removing the sun glint effect. For the water column correction, it would be advantageous to test the use of models such as the one of Lyzenga $(1978,1981)$ in the absence of bathymetric data or the one of Sagawa et al. (2010), which requires bathymetry data.

\section{ACKNOWLEDGEMENTS}

The authors thank Mélanie-Louise Leblanc for sharing her knowledge on the Tabusintac lagoon and for helping with the atmospheric correction of the image. The study was funded by an Atlantic Ecosystem Initiative grant awarded to the Southern Gulf of St. Lawrence Coalition on Sustainability. David Forsey was also supported by a MITACS Accelerate grant awarded to Dr. A. LaRocque. Stantec Creativity \& Innovation Fund covered the ground truth data collection and much of Dr. Skinner's time on this project. Public Services and Procurement Canada funded the original mapping project (Stantec, 2014, 2016), and the 2008 map was shared by Drs. Mahoney and Hanson from the Canadian Wildlife Service in Sackville (NB).

\section{REFERENCES}

Barrell, J., Grant, J., Hanson, A., Mahoney, M., 2015. Evaluating the complementarity of acoustic and satellite remote sensing for seagrass landscape mapping. Int J Remote Sens, 36(16), 4069-4094.

Berk, A., Bernstein, L.S., Anderson, G.P., Acharya, P.K., Robertson, D.C., Chetwynd, J.H., Adler-Golden, S.M., 1998. MODTRAN cloud and multiple scattering upgrades with application to AVIRIS. Remote Sens Environ, 65, 367-375.

Birth, G.S., McVey, G.R., 1968. Measuring colour of growing turf with a reflectance spectrophotometer. Agron J, 60, 640-649.

Breiman, L., 2001. Random Forests. J Mach Learn, 45(1), 5-32.

Buschmann, C., Nagel, E., 1993. In vivo spectroscopy and internal optics of leaves as basis for remote sensing of vegetation. Int J Remote Sens, 14(4), 711-722.

Byatt, J., LaRocque, A., Leblon, B., Harris, J., McMartin, I., 2018. Mapping surficial materials in Nunavut using RADARSAT-2 C-HH and C-HV, Landsat-8 OLI, DEM, and slope data. Can J Remote Sens, 44(5), 491-512. 
CBCL Limited, 2014. Coastal study for harbour access at Tabusintac Bay, New Brunswick. Report \# 131251.01-RE-001 for Public Works and Government Services Canada.

Chen, C.-F., Lau, V.-K., Chang, N.-B., Son, N.-T., Tong, P.-H.S., Chiang, S.-H., 2016. Multi-temporal change detection of seagrass beds using integrated Landsat TM/ETM+/OLI imageries in Cam Ranh Bay, Vietnam. Ecol Inform, 35, 43-54

Cohen, J., 1960. A coefficient of agreement for nominal scales. Educ Psychol Meas, 20(1), 7-46.

Collins, K., Webster, T., Crowell, N., McGuigan, K., MacDonald, C., 2016. Topo-bathymetric Lidar and photographic survey of various bays located in NB, NS, and PEI. Technical Report, Applied Geomatics Research Group, NSCC, Middleton (NS)

Congalton, R.G., 1991. A review of assessing the accuracy of classifications of remotely sensed data. Remote Sens of Environ, 37(1), 35-46.

Dekker, A., Brando, V., Anstee, J., Fyfe, S., Malthus, T., Karpouzli, E., 2006. Remote sensing of seagrass ecosystems: use of spaceborne and airborne sensors, 347-359. In Larkum, A.W.D., Orth, R.J., Duarte, C.M. (Eds). Seagrasses: Biology, Ecology, and Conservation. Springer, ISBN-10 1-4020-2983-7.

DFO, 2009. Does eelgrass (Zostera marina L.) meet the criteria as an ecologically significant species? Department of Fisheries and Oceans, Canadian Science Advisory Secretariat, Research Document n²009/018. Retrieved from: http://wavesvagues.dfo-mpo.gc.ca/Library/337549.pdf

Digital Globe, 2010. Radiometric use of WorldView-2 imagery: Technical note. Retrieved from:

https://www.digitalglobe.com/resources/technical-information

ESRI, 2014. ArcGIS®, version 10.2. Environmental Systems Research Institute, Redlands, CA.

Exelis Visual Information Solutions, 2013. ENVI®, version 5.1. Exelis Visual Information Solutions, Boulder (Colorado, USA).

Gislason, P.O., Benediktsson, J.A., Sveinsson, J.R., 2006. Random Forests for land cover classification. Pattern Recogn Lett 27(4), 294-300.

Heck, K.L. Jr., Orth, R.J., 2006. Predation in seagrass beds, 537-550. In Larkum, A.W.D., Orth, R.J., Duarte, C.M. (Eds). Seagrasses: Biology, Ecology, and Conservation. Springer, ISBN-10 1-4020-2983-7

Hedley, J.D., Harbone, A.R., Mumby P.J., 2005. Simple and robust removal of sun glint for mapping shallow-water benthos. Int J Remote Sens, 44, 2107-2112

Hogrefe, K., Ward, D., Donnelly, T., Dau, N., 2014.

Establishing a baseline for regional-scale monitoring of eelgrass (Zostera marina) habitat on the lower Alaska Peninsula. Remote Sensing, 6(12), 12447-12477.

Horning, N., 2010. Random Forests: an algorithm for image classification and generation of continuous field data sets. New York, American Museum of Natural History, Center for Biodiversity and Conservation. Retrieved from: http://gisws.media.osaka-cu.ac.jp/gisideas10/viewpaper.php ?id=342

Hossain, M.S., Bujang, J.S., Zakaria, M.H., Hashim, M., 2015. The application of remote sensing to seagrass ecosystems: an overview and future research prospects. Int J Remote Sens, 36(1), 61-114.

Hossain, M.S., Hashim, M., Bujang, J.S., Zakaria, M.H., Muslim, A.M., 2019. Assessment of the impact of coastal reclamation activities on seagrass meadows in Sungai Pulai estuary, Malaysia, using Landsat data (1994-2017). Int J Remote Sens, 40(9), 3571-3605.

IBA Canada, 2013. Important Bird Areas in Canada. Web. Accessed July 2017. Retrieved from: https://www.ibacanada.ca/site.jsp?siteID=NB002\&lang=EN\&fr ame $=$ null \&version $=2013 \&$ range $=A \&$ seedet $=\mathrm{N}$.

Kenny, A.J, Cato, I., Desprez, M., Fader G., Schüttenhelm, R.T.E., Side, J., 2003. An overview of seabed-mapping technologies in the context of marine habitat classification, ICES J Mar Sci, 60(2), 411-418.

LaRocque, A., Leblon, B., Woodward, R., Mordini, M., Bourgeau-Chavez, L., Landon, A., Camill, P., 2014. Use of Radarsat-2 and ALOS - PALSAR SAR images for wetland mapping in New Brunswick. 2014 IEEE Geoscience and Remote Sensing Symposium, Quebec City, QC, 2014, 12261229.

Leblanc, M.-L., LaRocque, A., Leblon, B., Hanson, A.R., Abraham, K., Humphries, M., 2019. Landsat time-series to evaluate seagrass dynamics: a case study in northeastern New Brunswick, Canada. $40^{\text {th }}$ Canadian Symposium in Remote Sensing, Fredericton (NB), June 4-6, 2019.

Lyons, M.B., Phinn S.R., Roelfsema, C.M., 2012. Long term land cover and seagrass mapping using Landsat and objectbased image analysis from 1972 to 2010 in the coastal environment of South East Queensland, Australia. ISPRS J Photogramm, 71, 34-46.

Lyzenga, D.R., 1978. Passive remote-sensing techniques for mapping water depth and bottom features. Appl Optics, 17, 379383.

Lyzenga, D.R., 1981. Remote sensing of bottom reflectance and water attenuation parameters in shallow water using aircraft and Landsat data. Int J Remote Sens, 10, 53-69.

Mahoney, M.L., Hanson, A.R., 2008. Distribution map of eelgrass (Zostera marina) in Tabusintac lagoon, New Brunswick, based on air photos. Canadian Wildlife Service, Environment and Climate Change Canada: Sackville, NB, Canada.

McFeeters. S.K. 1996. The use of the Normalized Difference Water Index (NDWI) in the delineation of open water features, Int J Remote Sens, 17(7), 1425-1432.

Mumby, P.J., Green, E.P., Edwards, A.J., Clark, C.D., 1997. Measurement of seagrass standing crop using satellite and digital airborne remote sensing. Mar Ecol Prog Ser, 159, 51-60.

O’Neill, J., Costa, M., 2013. Mapping eelgrass (Zostera marina) in the Gulf Islands National Park Reserve of Canada using high 
spatial resolution satellite and airborne imagery. Remote Sens Environ, 133, 152-167.

Orth, R.J., Moore, K.A., 1984. Distribution and abundance of submerged aquatic vegetation in Chesapeake Bay: a historical perspective. Estuaries, 7(4), 531-540.

Pal, M., 2005. Random Forest classifier for remote sensing classification. Int J Remote Sens, 26(1), 217-222.

PCI Geomatics, 2018. PCI Geomatica® Software, Version 2018, Markham (ON, Canada).

Pu, R., Bell, S., Meyer, C., Baggett, L., Zhao, Y., 2012. Mapping and assessing seagrass along the western coast of Florida using Landsat TM and EO-1 ALI/Hyperion imagery. Estuarine, Coastal and Shelf Science, 115, 234-245.

R Development Core Team, 2016. R: A language and environment for statistical computing. R Foundation for Statistical Computing, Vienna, Austria. Retrieved from: http://www.R-project.org/.

Ramsar, 2001. Tabusintac lagoon and river estuary. Web. Accessed June 2015. Retrieved from: https://rsis.ramsar.org/ris/612

Reshitnyk, L., Costa, M., Robinson, C., Dearden, P., 2014. Evaluation of WorldView-2 and acoustic remote sensing for mapping benthic habitats in temperate coastal Pacific waters. Remote Sens Environ, 153, 7-23.

Richards, J.A., Jia, X., 2006. Remote sensing digital image analysis: an introduction. Springer. New York. ISBN 978-3642-30062-2.

Rouse, J.W., Haas, R.H., Schell, J.A., Deering, D.W., 1974. Monitoring vegetation systems in the Great Plains with ERTS. Third ERTS Symposium, NASA SP-351 I, 309-317.

Sagawa, T., Boisnier, E., Komatsu, T., Mustapha, KB., Hattour, A., Kosaka, N., Miyazaki, S., 2010. Using bottom surface reflectance to map coastal marine areas: a new remote sensing method. Int J Remote Sens, 31: 3051-3064.

Short, F., McKenzie, L.J., Coles, R.G., Vidler, K.P., Gaeckle, J.L., 2007a. SeagrassNet manual for scientific monitoring of seagrass habitat. Worldwide edition. University of New Hampshire Publication.

Short, F., Carruthers, T., Dennison, W., Waycott, M., 2007b. Global seagrass distribution and diversity: A bioregional model. J Exp Mar Biol Ecol, 350(1-2), 3-20.

Sripada, R.P., Heiniger, R.W., White, J.G., Meijer, A.D., 2006. Aerial color infrared photography for determining early inseason nitrogen requirements in corn. Agron J, 98, 968-977.

Stantec, 2014. Remote sensing of eelgrass at Tabusintac (NB), Final Report for Public Works and Government Services Canada, Moncton (NB), Stantec Consulting Ltd., Dartmouth, Nova Scotia.

Stantec, 2016. Accuracy assessment of remote sensing methodologies for Tabusintac Bay, New Brunswick. Report for the Canadian Wildlife Service, Environment Canada, Sackville
(NB), Stantec Consulting Ltd, Dartmouth, Nova Scotia. Final Report \# 121413924.

Strahler, A.H., 1980. The use of prior probabilities in maximum likelihood classification of remotely sensed data. Remote Sens Environ, 10(2): 135-163.

Thom, R., Southard, S., Borde, A., 2013. Climate-linked mechanisms driving spatial and temporal variation in eelgrass Zostera marina L. Growth and assemblage structure in Pacific Northwest estuaries. J Coastal Res, 68, 1-11.

Tucker, C.J., 1979. Red and photographic infrared linear combinations for monitoring vegetation. Remote Sens Environ, $8,127-150$.

Waske, B., Braun, M., 2009. Classifier ensembles for land cover mapping using multitemporal SAR imagery. ISPRS $J$ Photogramm, 64 (5), 450-457.

Waycott, M., Duarte, C.M., Carruthers, T.J.B., Orth, R.J., Dennison, W.C., Olyarnik, S., Calladine, A., Fourqurean, J.W., Heck Jr., K.L., Hughes, A.R., Kendrick, G.A., Kenworthy, W.J., Short, F.T., Williams, S.L., 2009. Accelerating loss of seagrasses across the globe threatens coastal ecosystems. Proceedings of the National Academy of Sciences of the United States of America, 106 (30), 12377-12381.

Webster, T., McGuigan, K., Crowell, N., Collins, K., MacDonald, C., 2015. Tabusintac 2014 topo-bathymetric Lidar and eelgrass mapping report. Technical report, Applied Geomatics Research Group, NSCC, Middleton (NS).

Wilson, K., Skinner, M.A., Lotze, H.K., 2019. Eelgrass (Zostera marina) and benthic habitat mapping in Atlantic Canada using high-resolution SPOT 6/7 satellite imagery. Estuarine, Coastal and Shelf Science, 106(15), 106292.

Zhang, Y., 2002. A new automatic approach for effectively fusing Landsat 7 as well as IKONOS images. IEEE International Geoscience and Remote Sensing Symposium (IGARSS 2002), Toronto, ON, Canada, 2429-2431.

Zimmerman, C., Dekker, A., 2006. Aquatic optics: basic concepts for understanding how light affects seagrasses and makes them measurable from space, 295-301. In Larkum, A.W.D., Orth, R.J., Duarte, C.M. (Eds). Seagrasses: Biology, Ecology, and Conservation. Springer, ISBN-10 1-4020-2983-7. 